\title{
PERFORMANCE OF AN AGRICULTURAL IMPACT SPRINKLER FITTED WITH PLASTIC
}

\section{NOZZLES}

\author{
Talel Stambouli ${ }^{1}$, Nery Zapata $^{2}$, Jose M. Faci ${ }^{3}$
}

${ }^{1}$ University of Carthage, Ecole Superieure d'Agriculture de, Mograne 1121, Tunisia

${ }^{2}$ Dept. Soil and Water, Experimental Station of Aula Dei (EEAD-CSIC), Apdo. 202, 50080 Zaragoza, Spain

${ }^{3}$ Soil and Irrigation Unit. Agrifood Research and Technology Center of Aragón(CITA-DGA), Gobierno de Aragón, Avda. Montañana 930, 50059 Zaragoza, Spain

\section{ABSTRACT}

The radial water distribution and irrigation performance of an agricultural sprinkler with plastic nozzles were analysed. Twenty-six tests with an isolated sprinkler corresponding to different combinations of three working pressure ( $p, 200,300$ and $400 \mathrm{kPa})$ and three nozzle diameters of the main nozzle $(4.0,4.5$ and $5.0 \mathrm{~mm})$ were performed to evaluate the radial water distribution curves, All the tests were performed under calm wind $\left(\leq 1 \mathrm{~m} \mathrm{~s}^{-1}\right)$ under open air conditions. Fifty tests corresponding to six combinations of nozzle diameter and pressure with the same sprinkler model were performed under a wide range of meteorological conditions in a rectangular solid-set system at $18 \mathrm{~m} \times 18 \mathrm{~m}$ sprinkler spacing to evaluate the Christiansen's Uniformity Coefficient (CUC) and wind drift and evaporation losses (WDEL). The resulting radial water distribution curves were compared with those from impact sprinklers with brass nozzles. Sprinkler model had an important effect on the radial water distribution, even under similar operational conditions, and these differences were shown in the first 2.5 to $6 \mathrm{~m}$ from the sprinkler. The CUC and WDEL of a solid-set sprinkler system were compared with simulated values from the "Ador-Sprinkler" model. The results of this analysis showed that the type of sprinkler had a moderate influence on sprinkler irrigation uniformity. The analysis presented in this study may serve to develop a decision tool to choose the most suitable combinations of sprinkler model, nozzle diameter and working pressure to optimise the uniformity and efficiency of sprinkler irrigation. 


\section{KEY WORDS:}

Impact sprinkler, plastic nozzle, radial distribution, uniformity, wind drift and evaporation losses 


\section{INTRODUCTION}

Knowledge of the water distribution along the wetted radius of an impact sprinkler is crucial to characterise the water distribution and uniformity of a solid-set sprinkler system. This relationship between the discharge and distance to the sprinkler is known as the radial curve of the sprinkler.

A representative measurement of the radial water distribution must be obtained under calm conditions to avoid the strong influence of wind on the sprinkler water distribution (Tarjuelo et al., 1999a). Ideally tests to obtain these curves should be obtained in indoor facilities but these facilities often are not available and tests usually have to be made under open-air conditions during calm periods. The absence of wind is necessary in order to obtain a reliable radial curves. Experiments made by Sánchez et al. (2011), where water was collected in four radii of pluviometers located in north, south, east and west directions around an isolated sprinkler, showed that even at low wind speeds where there is a dominant wind direction important changes can be seen They found that there was a threshold value of 0.6 $\mathrm{m} \mathrm{s}^{-1}$ for the reliable determination of radial curves in open air conditions.

The uniformity of a solid-set system under calm conditions can be assessed through the overlap of the individual water distribution of sprinklers at the selected sprinkler spacing (Tarjuelo et al. 1999a). Theoretically, under calm conditions the overall water distribution derived from the radial water distribution curve is circular. However, under field conditions usually the sprinkler distributions are deformed due to wind speed and direction. The determination of sprinkler uniformity at the farm level requires the on-site evaluation of a sprinkler system under different field operation conditions or the use of mathematical simulation models that take into account the modification of the sprinklers water distribution due to the design and management parameters which affect performance. The models require a knowledge of the radial water distribution curve to facilitate evaluation of sprinkler irrigation under a wide range of management and environmental conditions with minimmum 
experimental effort (Carrión et al., 2001; Lorenzini and De Wrachien., 2005; Playán et al., 2006).

The performance of sprinkler irrigation depends on design and operational factors. The most important design factors are the sprinkler type, the use of one or two nozzles, nozzle diameters and sprinkler spacing. Operational factors include working pressure, the time of irrigation and environmental conditions during irrigation, mainly wind speed (Keller and Bliesner, 1990; Carrión et al., 2001; Playán et al., 2006).

Irrigation uniformity and wind drift and evaporation losses (WDEL) are usually the parameters used to define the irrigation performance of solid-set sprinkler irrigation systems. Generally, distribution uniformity equations such as the Christiansen uniformity coefficient (CUC, Christiansen, 1942) are the main parameters used to determine whether an irrigation system is acceptable or not (Brennan, 2008). Sánchez et al., 2010a and 2010b compared CUC and WDEL in solid-set sprinkler irrigating maize and alfalfa and found that the sprinkler performance parameters were also affected by the height of the pluviometers where the water application was measured and by the height and type of the crop canopy.

Wind speed is the meteorological variable more directly related with the irrigation performance through its effects on the CUC and WDEL (Playán et al., 2005). Faci and Bercero (1991) found that the CUC of solid set sprinklers decreased when wind speed was greater than $2 \mathrm{~m} \mathrm{~s}^{-1}$. Dechmi et al. (2003) and Playán et al. (2006) found that the CUC of lateral movement irrigators was less affected by wind speed than solid-sets.

The solid-sets that are used in the Ebro River Basin, Spain incorporate metallic impact sprinklers with brass bodies and brass nozzles screwed into the body of the sprinkler. When these nozzles are blocked it is necessary to use a tool to unscrew the nozzles and clean them. This task is made more difficult because the sprinklers often are installed at $2.3 \mathrm{~m}$ above ground level and also the jet straightening vane located inside the main nozzle can be lost during the unblocking process. In order to avoid these problems some sprinkler 
manufacturers have developed sprinklers with brass or plastic bodies and plastic nozzles that can be easily removed or inserted in the body of the sprinklers by hand using a bayonet fitting. These plastic nozzles have some parallel lines engraved into the inside of the nozzle in the direction of the water flow to avoid the use of the jet straightening vane. The engraved parallel have the same function as the straightening vane; by making the jet more compact they achieve a greater throw and decrease the influence of wind. It has been shown that when using a straightening vane at wind speeds higher than $2 \mathrm{~m} \mathrm{~s}^{-1}$, CUC values are higher (Tarjuelo et al., 1995).

More detailed technical information is needed in order to know the possible advantages and the irrigation performance of using this design of plastic nozzle. This study includes the determination of the radial curve of an impact sprinkler with brass body and plastic nozzles operating at different working pressures with different diameters of the main nozzle. This study also analyses the irrigation uniformity of a solid set equipped fitted with this type of sprinkler. Results of tests to determine the radial water distribution curve and the overall water distribution achieved by a solid-set were compared with results obtained from metal impact sprinklers fitted with the traditional brass nozzles and operated in the same experimental conditions.

\section{MATERIAL AND METHODS}

Experiments were conducted at the experimental farm of the Agrifood Research and Technology Centre of Aragón in Zaragoza, Spain (414ㄱ' N, 048' W, 225 m altitude) during 2009 and 2010. Two sets of experiments were performed. The first set was carried out using a single sprinkler located above bare soil. The second set of experiments was performed using a solid set of sprinklers mounted at a rectangular spacing of $18 \mathrm{~m} \times 18 \mathrm{~m}$. The experiments were made taking into consideration the recommendations of Merriam and Keller (1978) and the relevant International Standards: ASAE S330.1 (Anonymous, 1987), ISO 7749/1 (Anonymous, 1995) and ISO 7749/2 (Anonymous, 1990). 
The sprinkler used in all experiments was the impact sprinkler model RC130-BY (Riegos Costa, Lleida, Spain $\left.{ }^{1}\right)$. The body of the sprinkler is made of brass provided with two outlets for the insertion of the plastic main and auxiliary nozzles, both with a bayonet coupling.

\subsection{Single sprinkler tests}

A single sprinkler, model $\mathrm{RC} 130 \mathrm{BY}$, was installed in a riser pipe at $2 \mathrm{~m}$ above ground level (a.g.I). The irrigation depth (ID) emitted by the sprinkler was collected in pluviometers located along four perpendicular radii at distances from the sprinkler ranging from 0.3 to $16.3 \mathrm{~m}$ and separated at $0.5 \mathrm{~m}$ (Fig. 1a). Additional pluviometers were installed at $0.15 \mathrm{~m}$ from the sprinkler in each radius to determine precisely the ID in the area adjacent to the sprinkler. A total number of 34 pluviometers were installed in each radius at $0.4 \mathrm{~m}$ above the ground level (Figure 1a). The radii of pluviometers faced north $(N)$, west $(W)$, south $(S)$ and east $(E)$ directions. Each pluviometer was $0.40 \mathrm{~m}$ high and conical with a circular opening of $0.16 \mathrm{~m}$. The pluviometers were marked with $1 \mathrm{~mm}$ intervals of precipitation. The experimental plot was surrounded by windbreaks trees to minimise the effect of the wind as shown in Fig. 1. Three inside diameters of the main nozzle were tested in the isolated tests: $4,4.5$ and $5 \mathrm{~mm}$. The sprinkler included in all tests a plastic auxiliary nozzle with $2.5 \mathrm{~mm}$ inside diameter. The sprinkler was operated at three ranges of working pressure $(200,300$ and $400 \mathrm{kPa})$. Since dead calm was not possible, the tests were performed under low wind conditions $\left(<1 \mathrm{~m} \mathrm{~s}^{-1}\right)$. The mean duration of the tests was $2 \mathrm{~h}$. Twenty six tests with different combinations of diameter and pressure were performed but only the nine tests with the lowest wind speed were selected to determine the radial curve (Table 1).

The working pressure in the isolated sprinkler installation was controlled with manual valves and a manometer installed in the head control of the experiment (Fig. 1a). The working pressure at the sprinkler was measured at 5-min intervals with a pressure transducer model

\footnotetext{
${ }^{1}$ The mention of trade names of commercial products in this chapter is solely for the purpose of providing specific information and does not imply recommendation or endorsement by the CITA-DGA or by the CSIC.
} 
PS series (Gems Sensors Inc., Basingstoke, Hampshire, UK), connected to a data logger (E120, Dixon, Addison, IL, USA) installed in the pipe riser at $200 \mathrm{~mm}$ below the sprinkler nozzles.

The wind speed and direction, air temperature and relative humidity were monitored by an automatic meteorological station located in an adjacent plot to the experimental site during the tests. A 3-cup rotors anemometer Series A-100 and a wind direction sensor model 024-L (Campbell Scientific Ltd., Shepshed, UK) were used to measure wind speed and direction, respectively. A model CS-215 probe (Campbell Scientific Ltd., Shepshed, UK) was used to measure temperature and relative humidity. The average records of the meteorological variables were collected every five minutes by a data-logger model CR10X (Campbell Scientific Ltd, Shepshed, UK). In each single sprinkler test, the depth of water collected at each distance from the sprinkler at each radius was averaged and the standard deviation calculated. The average radial distribution from each combination of nozzle diameter and pressure was used to calculate the CUC under calm conditions using a rectangular sprinkler spacing of $18 \mathrm{~m} \times 18 \mathrm{~m}$ equivalent to the spacing used for the solid-set experiment.

For each combination of nozzle diameter and pressure used in the single sprinkler test with the smallest differences between the four radii were used to characterise the radial water distribution. For each test, the average standard deviation of the collected irrigation depth in the individual test $\left(\mathrm{SD}, \mathrm{mmh}^{-1}\right)$ was calculated as the average value of the 34 positions in the four radii.

The water discharge of the isolated sprinkler $\left(\mathrm{Q}, \mathrm{I} \mathrm{s}^{-1}\right)$ was measured with a water meter Model 002011 (Fecosan, Zaragoza, Spain) installed in the head control of the experiment as the difference between the flow meter reading at the end and the beginning of each isolated sprinkler isolated test (Fig. 1a). The volumetric water meter had a precision of $0.1 \mathrm{I}$. 
The Torricelli's theorem and the orifice equation, (Norman et al. 1990) was used to calculate the discharge coefficient $\left(C_{D}\right)$ of the sprinkler for each combination of diameter and pressure, that is expressed as:

$$
Q=C_{D} \times A \times(2 g p)^{k}
$$

Where $C_{D}$ is the discharge coefficient, $A$ the area of the nozzles orifices $\left(\mathrm{mm}^{2}\right), g$ gravitational acceleration $\left(\mathrm{m} \mathrm{s}^{-2}\right)$. $p$ pressure in nozzle $(\mathrm{kPa})$, and $k$ a constant.

Concerning Eq. 1, several studies applied to agricultural sprinklers interpreted that $C_{D}$ is essentially independent of pressure for a given nozzle and that $k$ is constant and equal to 0.5 (Li, 1996; Li and Kawano, 1998; Tarjuelo et al., 1999a). In the present work it was assumed that $k$ was equal to 0.5 and a single $C_{D}$ was determined for each sprinkler nozzle diameters working at different pressures.

Three sprinkler models were compared: the RC130-BY evaluated in this research, the RC130-L evaluated by Playán et al. (2006) and the VYR-35 evaluated by Zapata et al. (2007). The two last sprinkler designs have brass bodies and nozzles and are widely used in the solid set systems in the Ebro Valley (Spain). The radial water distribution was compared for these three sprinklers.

\subsection{Solid set experiment}

The solid set tests were tested in an experimental plot equipped with 16 sprinklers (RC130BY) fitted with plastic nozzles at a regular spacing of $18 \mathrm{~m} \times 18 \mathrm{~m}$ (Fig. 1.b). The working pressure in the sprinkler solid-set was measured using a pressure transducer using the same method that was used in the isolated tests. Irrigation performance was evaluated using the collected irrigation depth in a network of 25 pluviometers installed at $3.6 \mathrm{~m} \times 3.6 \mathrm{~m}$ in the area between the four sprinklers located in the centre of the experimental field (Fig. 1b). Each pluviometer represents an area of $13 \mathrm{~m}^{2}$. Rows of horizontal plastic platforms were installed in the experimental area in order to facilitate the access to measure the collected depth of water in the pluviometers. The CUC and WDEL were assessed from the water 
depth collected in the pluviometers. The same type of pluviometer as used in the isolated sprinkler tests was used.

The CUC in each solid-set evaluation was calculated using the following equation (Christiansen, 1942):

$$
\text { CUC }=100 \times\left(1-\frac{\sum_{i=1}^{i=25}\left|h_{m}-h_{i}\right|}{n \times h_{m}}\right)
$$

Where $n$ is the number of pluviometers, $h_{m}$ is the mean water depth collected and $h_{i}$ is the water depth collected in pluviometer $I$.

The water depth emitted by the sprinkler $\left(I D, I \mathrm{~m}^{-2}\right)$ was calculated in each solid-set test using the following equation:

$$
I D=\frac{Q t}{S}
$$

Where $Q$ is water discharged $\left(\mathrm{I} \mathrm{s}^{-1}\right)$ calculated using Eq. 3, $\mathrm{t}$ is the duration of the test (s), and Sis sprinkler spacing which in the experimental solid-set was $18 \times 18=324 \mathrm{~m}^{2}$ The discharge of the sprinkler $\left(Q, I \mathrm{~s}^{-1}\right)$ was estimated using Eq. 1 with the calculated $C_{D}$ values obtained in the isolated sprinkler tests.

The WDEL during each test was estimated as the percentage of the water depth emitted by the sprinklers (ID) that was not collected in the pluviometers (Dechmi et al., 2003; Playán et al., 2005; Sanchez et al., 2010a):

$$
W D E L=\frac{I D-I D_{C C}}{I D} \times 100
$$

Where $I D_{C C}$ is the mean water depth collected in the pluviometers and $I D$ the mean water depth emitted by the sprinkler. 
Solid-set evaluations were performed under a wide range of meteorological conditions in an attempt to characterise the CUC and the WDEL resulting from different combinations of nozzle diameter and pressure. The meteorological variables during the duration of the tests were monitored at 5-min intervals by an automatic meteorological station similar to the one used during the sinlge-sprinkler tests. The meteorological station was located in an adjacent plot to the solid-set experimental plot. A multiple regression analysis was performed to investigate the variation of the CUC and of the WDEL with irrigation duration, nozzle diameter, operating pressure, wind speed, air temperature and relative humidity. The suitable predictive equations of CUC and WDEL as a function of technical and meteorological variables were selected through a backward stepwise procedure accounting for their statistical indicators used to monitor and compare the selected equations (Dolado, 1999). The adjusted coefficient of determination (adjusted $R^{2}$ ), the mean square error (MSE), the coefficient of efficiency (E) defined by Wilcox et al. (1990), the similarity index (IS) (Willmott, 1981) and the root mean square error (RMSE) were analysed. Two additional statistics parameters were introduced to evaluate the predictive capability of the equations: the average magnitude of the relative error (AMRE, \%) and the prediction level 25 (Pred [0.25]) (Dolado, 1999). The Pred [0.25] is the percentage of the estimated values differing from the measured value by less than 25\% (Dolado, 1990 and Playán et al., 2005).

The irrigation performance (CUC and WDEL) under the different wind conditions of the experimental solid set configuration of R $18 \times 18$ equipped with the sprinkler RC130-BY was compared with the experimental data of a solid set at a triangular spacing of $18 \mathrm{~m}$ by $18 \mathrm{~m}$ equipped with the sprinkler RC130-L (Playán et al., 2006).

Finally, the CUC and the WDEL of a solid set with the same spacing as the experimental solid-set (R18x18) was simulated for the same experimental sprinkler model but with the brass nozzles for the same operating and meteorological conditions of the evaluation tests using the ballistic model Ador-sprinkler (Dechmi et al. 2004 a; b and Playán et al., 2006). 
The Ador-sprinkler model applies ballistic theory to determine water distribution resulting from sprinklers subjected to a wind vector (Dechmi et al., 2003). The model uses a drop size distribution equation whose parameters depend on the sprinkler type, nozzle diameters, meteorological conditions and operating pressure.

\section{RESULTS AND DISCUSSION}

\subsection{Isolated sprinkler tests}

The parameter $C_{D}$ of Eq. 1 was assessed by a nonlinear regression analysis of the evaluated values of $Q$ fitted to a power curve. The calculated values of $C_{D}$ for the inside nozzle diameters $(D)$ of $4.0+2.5,4.5+2.5$ and $5.0+2.5 \mathrm{~mm}$, were $0.940,0.953$ and 0.971 , respectively. A very slight increase of the $C_{D}$ was found as the $D$ of the sprinkler nozzle increased.

A summary of the results of the 26 tests performed in the isolated-sprinkler experiment to assess the radial water distribution for different combinations of $D$ and $p$ are presented in Table 1. The average irrigation time of the isolated sprinkler tests was $2.1 \mathrm{~h}$ but this ranged between 1.9 and $3.5 \mathrm{~h}$. Most of the tests were started under calm conditions but in some cases the wind speed increased during the test changing the water distribution and increasing the standard deviation of the ID $\left(\mathrm{mm} \mathrm{h}^{-1}\right)$ in the four radially positioned pluviometers. In outdoor experiments it is almost impossible to perform the test under totally calm conditions. There is always wind even though it may be imperceptible. The average wind velocity during all the single sprinkler tests was $0.8 \mathrm{~m} \mathrm{~s}^{-1}$ but it ranged from 0.3 to $1.5 \mathrm{~m}$ $s^{-1}$.

The radial water distribution for each test was calculated from the mean of the water distribution in the four radii. This is based on the concept that the distribution of the water applied must be equal in the four radii under calm conditions. However, the distribution of water collected was noticeably differed between the radii in many tests, both in the shape 
and in the total volume of water collected (data not shown). Table 1 presents the average values of the standard deviation of $I D\left(\mathrm{~mm} \mathrm{~h}^{-1}\right)$ along the four radii. This value summarises the similarity of the water distribution obtained in the four radii of pluviometers in each isolated sprinkler test. The average value for all tests was $0.29 \mathrm{~mm} \mathrm{~h}^{-1}$ and ranged from 0.1 to $0.8 \mathrm{~mm} \mathrm{~h}^{-1}$.

Wind speed was not the only variable affecting the radial distribution. Results showed that the wind direction was also a variable that affected the radial water distribution. Sánchez et al. (2011) found that prevailing winds, even at very low speeds, a significant volume of water drifted. For this reason, it was necessary to evaluate the predominant wind direction before selecting a suitable radial water distribution. The dominant wind direction frequency for all single sprinkler tests is presented in Table 1. For the selected single sprinkler tests used to determine the radial water distribution (marked in bold in Table 1) the dominant wind direction frequency did not exceeded the $33 \%$ of the experimental time and therefore, the irrigation water distributions was clearly not displaced in one direction and the collected ID in the four radii of pluviometers were similar. The average values of the standard deviation of $I D$ $\left(\mathrm{mm} \mathrm{h}^{-1}\right)$ along the four radii of the selected radial water distribution ranged from 0.11 to 0.19 $\mathrm{mm} \mathrm{h}^{-1}$.

Finally, eight selected radial water distribution curves were obtained for the three nozzle diameters $(4.0+2.5,4.5+2.5$ and $5.0+2.5 \mathrm{~mm})$ and three working pressure $(200,300$ and 400 $\mathrm{kPa}$ ) combinations (Fig. 2). The single sprinkler test performed for the combination of nozzle diameters $5.0+2.5 \mathrm{~mm}$ and working pressure of $400 \mathrm{kPa}$ was not adequate to determine the radial water distribution curve due to a wind speed of $1.5 \mathrm{~m} \mathrm{~s}^{-1}$ and a predominance of a wind direction (Table 1). 


\subsection{Comparison of radial curves of sprinklers with plastic and brass nozzles}

The radial patterns obtained with the sprinkler model RC130-BY (Fig. 2) in the present work, were compared with the existing radial water distribution curves for sprinkler models RC130L and VYR-35 obtained in previous works using the same experimental facilities (Playán et al., 2006; Zapata et al., 2007). Comparisons were made by the method of paired samples, using the data of the tests of the different sprinkler models performed for the same nozzle diameter and operating pressure.

Figure 2 shows the mean radial water distribution curve for the three sprinkler models and combinations of nozzle diameter and pressure. It should be noted that there are some differences in the nozzle diameters and pressures between models. All the models included an auxiliary nozzle with a $2.5 \mathrm{~mm}$ inside diameter for the RC130-BY sprinkler and $2.4 \mathrm{~mm}$ internal diameter for the RC130-L and VYR-35 sprinklers. The RC 130-L and the VYR-35 sprinklers included a straightening vane in the main nozzle. The radial water distribution noticeably differed between models (Fig. 2). Since the sprinklers presented similar configuration of nozzles (except for the 4.5 and the $5.0 \mathrm{~mm}$ diameters of the plastic nozzles of the RC130-BY model, that were close to the 4.4 and $4.8 \mathrm{~mm}$ diameters used for the two other sprinkler models). The different shape of the radial water distribution curves found between the sprinkler models was mainly due to the inner design of the body of the sprinklers and nozzles. As shown in Fig. 2, the RC130-BY sprinkler distributed less water 2.5 $\mathrm{m}$ to $6 \mathrm{~m}$ distance from the sprinkler compared with the two other models, except for the two cases shown in Figs. 2.g and h, where the water depth produced by the RC130-BY was always larger than that from the VYR35. This could be due to the difference in the main nozzle diameters of the two sprinkler models $(5.0 \mathrm{~mm}$ for the RC130-BY and $4.8 \mathrm{~mm}$ for the VYR35).

Three typical shapes of radial water distribution curves have been reported in the literature: triangular, rectangular and donut (or toroidal). The triangular shape corresponds usually to 
the use of sprinklers with two nozzles, the rectangular shape to the use of sprinklers with one nozzle without SV, and the donut shape to the combinations of sprinklers with one nozzle operating at very low pressure (Tarjuelo et al., 1999a). The radial water distribution curves for the presented sprinklers did not match any of the three typical shapes but were combinations of them. Changes in main nozzle, or in the operating pressure, had more influence on the amount of water delivered by the sprinkler than on the shape of the radial water distribution curve. Tarjuelo et al. (1999a) reported that the shape of the radial water distribution curve is mainly determined by the sprinkler model and its internal design, the discharge angle and by the jet break-up mechanism of the sprinkler.

The paired samples analysis showed that only two radial water distribution patterns were statistically similar: the RC130-BY with the combination of $4.5 \mathrm{~mm}$ at $300 \mathrm{kPa}$ and the RC130$\mathrm{L}$ with the combination of $4.4 \mathrm{~mm}$ at $300 \mathrm{kPa}$ (Fig. 2.e). The other comparisons for the different sprinkler models and combinations of nozzle diameter and pressure were different in shape.

\subsection{Solid-set experiment}

Fifty tests corresponding to different combinations of nozzle diameter and pressure were carried out in the solid-set experiment using the sprinkler model RC130-BY under a wide range of meteorological conditions. Operating pressure in the different solid set evaluations varied between 188 and $392 \mathrm{kPa}$ (Table 2). The average duration of the solid set evaluations was around $2.2 \mathrm{~h}( \pm 0.31 \mathrm{~h})$ and varied from a minimum of $1.6 \mathrm{~h}$ to a maximum of $3.3 \mathrm{~h}$. The wind speed in the different evaluations varied between 0.16 and $7.60 \mathrm{~m} \mathrm{~s}^{-1}$. The average temperature for the tests was $21.7^{\circ} \mathrm{C}$ with values ranging from 7.8 to $30.1^{\circ} \mathrm{C}$. In general the evaluations of the solid-set for different main nozzle diameters were performed for similar conditions of air temperature and relative humidity except in a few individual tests for the $4+2.5$ and $5+2.5 \mathrm{~mm}$ nozzle diameters where the temperature was significantly lower than the average. 
The performance parameters CUC and WDEL of the solid set evaluations showed an ample range of variation. The CUC of individual tests varied from $51 \%$ to $93 \%$ and WDEL varied from $0 \%$ to $36 \%$ depending mainly on the operation and meteorological conditions (Table 2 ).

The effects of wind speed, main nozzle diameter, operating pressure and other meteorological variables on CUC and on WDEL were assessed using backward stepwise analysis to select the best suited model for the prediction of these parameters in solid set with the sprinkler model RC130-BY. The best model found for the prediction of the CUC (\%) was a linear function of wind speed $U\left(\mathrm{~m} \mathrm{~s}^{-1}\right)$ (Figure 3). The following equation was obtained:

$\operatorname{CUC}(\%)=90.31-4.40 * U$

$$
\left(R^{2}{ }_{\text {dj }}=0.75 ; R M S E=1.9 \%\right)
$$

This linear regression shows that there is a negative relationship between the CUC and the independent variable $U$. The mean absolute error (MAE) for this equation was very low, less than $0.05 \%$, the coefficient of efficiency (E) and the Similarity Index (IS) were 0.7 and 1.0 respectively and very close to 1.0 presenting a better agreement between observed and predicted CUC values. The Pred [0.25] indicates that the $100 \%$ of the predicted CUC differed from the measured CUC by less than $25 \%$.

Data points in Fig. 3 respresent the experimental data of the CUC values obtained in the 50 solid-set evaluations with the RC130-BY sprinklers. In Fig. 3, the relationship found by Playán et al. (2006) for a triangular solid-set at $18 \mathrm{~m} \times 18$ spacing with the sprinkler model RC130-L with nozzle diameters of $4.4+2.5 \mathrm{~mm}$ is also presented for comparison purposes (dashed line). Both equations are similar in slope but the line of the RC130-L data is above the line of the experimental sprinkler RC130-BY. However, it is important to indicate that the experimental conditions were different. The sprinkler spacing was rectangular in the case of the RC 130-BY but triangular in the case of the RC 130-L. The nozzle diameter were different and the range of wind speed varied between 1.0 and $7.6 \mathrm{~m} \mathrm{~s}^{-1}$ in the case of the BY 130-BY sprinkler and between 0.6 and $4.4 \mathrm{~m} \mathrm{~s}^{-1}$ in the case of the RC 130-L sprinkler. 
Several studies have shown that the wind is the main environmental factor affecting sprinkler irrigation performance (Seginer et al., 1991a y 1991b; Kincaid et al., 1996; Dechmi et al., 2004a, b; Playán et al., 2005; Sanchez et al., 2010a, b; Tarjuelo et al., 1999c; Yu et al., 2009; Sánchez et al., 2011; Stambouli et al, 2012). In agreement with these studies, in this work the wind speed decreased CUC (Fig. 3) and increased WDEL (Fig. 4). The wind speed has also been reported by several authors (Playán et al., 2005; Zapata et al., 2007; Sánchez et al., 2011) as the most significant variable affecting the WDEL. However the selection of the predictor variables was more complicated in the case of the WDEL than in the case of CUC. When all the variables were included, only $U$ and $D$ were found significant (data not shown). Both variables have been previously selected among the predictor variables of the WDEL in other studies in sprinkler irrigation (Faci et al., 2001;; Keller and Bliesner, 1990; Tarjuelo et al., 2000). The operating pressure was not significant in the present work although it has been included in many previous studies (Keller and Bliesner, 1990; Montero, 1999; Tarjuelo et al., 2000; Yazar, 1984).

The best suited equation obtained to predict WDEL (\%) uses the wind speed $\left(\mathrm{U}, \mathrm{m} \mathrm{s}^{-1}\right)$ and the nozzle diameter $(\mathrm{D}, \mathrm{mm})$ as the explicative variables (statistical significance $\alpha=0.01$ ) (Eq. 6).

$\operatorname{WDEL}(\%)=22.31-4.56^{*} \mathrm{D}+3.93^{*} \mathrm{U} \quad\left(\mathrm{R}^{2}{ }_{\mathrm{adj}}=0.85 ; \mathrm{RMSE}=1.4 \%\right)$

A relatively high adjusted determination coefficient was obtained $\left(R^{2}\right.$ adj $\left.=0.85\right)$. MAE, IS, $E$ and Pred [0.25] were $0.01,0.99$ and $0.9,55 \%$ respectively. For conditions similar to those of this study, the regression equation obtained for all irrigation events to predict WDEL as a function of $U$ and $D$ would be recommended. However, to compare sprinkler models RC130BY and RC130-L, a linear relationship between WDEL and $U$ was obtained with the experimental results of the solid-set experiment presented in Fig. 4. The determination coefficient $\left(R^{2}\right)$ was 0.82 , slightly lower than the value obtained when wind speed and main nozzle diameter were included in the model (Eq. 6). 
The linear regression of WDEL and U found by Playán et al (2006) for a solid set with the sprinkler model RC130-L with $4.4+2.4 \mathrm{~mm}$ nozzle diameters had a higher slope and lower value of the $\mathrm{R}^{2}$ (Fig. 4). However the comparison is limited since the experimental conditions and the range of wind velocities in their solid-set evaluations was narrower than in our evaluations.

The importance of main nozzle diameter and pressure in the performance of the sprinkler irrigation is explained through their effects on the atomisation process. Recent investigations are focused on the atomization of the water jet released by the agricultural sprinklers (Bautista-Capetillo et al., 2009; King et al., 2010; Playán et al., 2010). The presented results showing the suitability of this line of research and pointing out that, in connection with this subject, manin nozzle diameter and pressure must be analysed together.

\subsection{Comparison of the measured (RC130-BY sprinkler) and simulated (RC130-L} sprinkler) irrigation performance of sprinkler solid-sets under the same operating and meteorological conditions.

In order to make a detailed and reliable comparison of solid-sets equipped with the RC130BY and RC130-L sprinkler models, the same sprinkler spacing and the same meteorological and operation conditions should be present in evaluations. As no experimental data with the RC130-L sprinkler were available under the same operation and meteorological conditions as our solid-set evaluations using the RC130-BY sprinkler, the irrigation performance indicators (CUC and WDEL) for the RC130-L sprinkler model, were simulated using the empirical model Ador-sprinkler (Playán et al., 2006). The same values of the operational and meteorological variables in our experiments (sprinkler spacing, nozzle diameters, time of irrigation, operation pressure, wind speed, average wind direction, air temperature and relative humidity) were introduced in the Ador-sprinkler model for the calculations.

The comparison was established for $D=4.0+2.5 \mathrm{~mm}$ and $4.5+2.5 \mathrm{~mm}$ for the RC130-BY sprinkler and $\mathrm{D}=4.0+2.4 \mathrm{~mm}$ and $4.4+2.4 \mathrm{~mm}$ for the RC130-L sprinkler. Table 3 presents 
the experimental results of the experimental solid-set with the s RC130-BY prinkler and simulated values of ID, WDEL and CUC for the RC130-L sprinkler under the same experimental conditions. No significant difference was found between the water discharges of both sprinkler models (data not showed) besides the slight difference in the nozzle diameters $(4.4+2.4 \mathrm{~mm}$ in the RC130-L sprinkler and 4.5+2.5 mm in the RC130-BY sprinkler) of both sprinklers.

In other studies, solid set sprinkler irrigation systems have been evaluated for different combinations of nozzle diameter and pressure (Playán et al., 2006; Tarjuelo et al., 1999b, 1999c; Sanchez et al., 2011). Some studies like that by Kincaid (1982) analysed the combined effect of nozzle diameter and pressure on the water distribution of the sprinklers, however, others authors highlighted the effects of D and $p$ separately. Kohl (1974) reported that the effect of nozzle diameter on the drop size distribution is smaller than the effect of pressure, apparently; the relationship between CUC and WDEL with the wind speed was affected by diameter and pressure. Apparently, these relationships differed depending on pressure, and these differences decreased when the nozzle diameter increased.

A comparison of the measured CUC and WDEL values from the experimental solid-set equipped with RC130-BY sprinklers and the simulated values for the same solid-set with the RC130-L sprinkler under the same operational and meteorological conditions is presented in Fig. 5. The comparison showed that the CUC is relatively similar in both sprinkler models. The linear regression had a determination coefficient of 0.67 . This relation showed slightly higher values of CUC for the RC130-BY sprinkler than for the RC130-L in the low range of CUC (<70\%) and lower values of CUC in the high range of CUC (>70\%). These results may be explained by a difference in the sprinkler models behaviour with the wind speed. In Table 3 the comparison between CUC values of the RC130-BY sprinkler and the RC130-L sprinkler for wind speeds $<1.5 \mathrm{~m} \mathrm{~s}^{-1}$, showed that the CUC for the two sprinkler models were almost equal (average difference in CUC was in order of $1.2 \%$ ). When wind speed ranged between 1.5 and $4 \mathrm{~m} \mathrm{~s}^{-1}$, the difference in CUC between the two sprinklers was high (average 
difference in CUC was around 10\%) with the RC130-L sprinkler showing higher CUC values. For higher wind speed $\left(>4 \mathrm{~m} \mathrm{~s}^{-1}\right)$, the difference in CUC between the two models was moderate (average difference in CUC was around 4\%) and the CUC of RC130-BY sprinkler was higher than the RC130-L sprinkler.

The linear regression of WDEL for both sprinkler models had a determination coefficient of 0.72 and showed a clear separation of the line $1: 1$. In the low range of WDEL $(<21 \%)$ the WDEL for the RC130-BY was lower than for the RC130-L sprinkler and for the high range of WDEL $(>21 \%)$ the opposite occurred. The lower experimental values of WDEL for the RC130-BY sprinkler compared to the simulated values of WDEL for the RC130-L sprinkler were mainly due to the prediction equation used in the Ador sprinkler simulation model. This equation to determine WDEL includes a constant value of $15 \%$ even under totally calm conditions and in our experimental conditions measurements of WDEL were frequently lower than this threshold value under calm or low wind speed.

Figure 6 presents a comparison of the water distribution patterns measured in three evaluations of the experimental solid-set under different levels on wind speed for the RC130BY sprinkler with the simulated water distribution patterns for the RC130-L sprinkler. Under low wind conditions $\left(U=1.6 \mathrm{~m} \mathrm{~s}^{-1}\right)$ (Fig. 6.a and b) a very high uniformity distribution was observed (CUC of $89 \%$ and $92 \%$ for RC130-L and RC130-BY respectively) in both sprinklers. Under moderate wind conditions $\left(\mathrm{U}=2.9 \mathrm{~m} \mathrm{~s}^{-1}\right)($ Fig. $6, \mathrm{c}$ and d) a lower value of CUC for the RC130-BY (76\%) than the simulated CUC for the RC130-L (88\%) was observed. For high wind conditions $\left(U=5.8 \mathrm{~m} \mathrm{~s}^{-1}\right)$ (Fig. 6, e and f) a slightly higher CUC was obtained for the RC130-BY sprinkler. The irrigation uniformity decreased with the wind speed (U). It can be observed (particularly in Figs 6. c, d, e and f) that the wind distortion of the water distribution pattern concentrated the precipitation in particular areas of the sprinkler spacing. The CUC of the experimental solid-set evaluations performed under wind speeds lower than the threshold value $\left(2 \mathrm{~m} \mathrm{~s}^{-1}\right)$ proposed by Faci and Bercero (1991), that 
represented $52 \%$ of the total number of irrigation evaluations, ) was larger than $62 \%$ (Table 3).

The water distribution pattern of a sprinkler layout is the result of the overlapping of the jets of water emitted by the sprinklers. Tarjuelo et al. (1999b) and Keller and Bliesner (1990) showed that water distribution pattern of solid set sprinkler irrigation systems was dependent on technical and meteorological conditions. For design purposes, the sprinkler model, nozzles sizes, operating pressure, sprinkler layout and sprinkler height above the soil are variables that should be considered.

The results obtained in this work showed that the selection of an adequate sprinkler is complex since its performance depends on many factors of different nature, many of them out of the control of the farmer. The knowledge of the radial water distribution curve of the sprinkler and empirical models such as Ador-sprinkler are useful for decision making since they allow the simulation of the sprinkler irrigation performance under very different conditions. However, thorough investigations are needed to acquire a better understanding about the processes involved in the formation and the atomisation of the jet and the evaporation and the drift of the resulting water drops. This is the path towards accurate physical models which should be valuable for the manufacturers of agricultural sprinklers, for farmers and society as a whole that needs and demands the efficient use of irrigation water.

\section{CONCLUSIONS}

The water distribution in a solid-set spacing depends greatly on the shape of the radial water distribution curve of the sprinkler selected. The information given in the sprinkler catalogues by sprinkler companies is often very limited and insufficient for sprinkler design purposes. The information of the standard radial water distribution of sprinklers should be included in sprinkler technical information since this information is important for an optimum sprinkler design. 
The results showed that characterisation of the radial water distribution of impact sprinkler with plastic nozzles in single sprinkler tests in open air conditions requires several precautions because the wind significantly distorts the water distribution pattern. As previously shown by Sanchez et al. (2011) with impact sprinklers with brass nozzles, it is recommended that evaluation tests of single sprinklers should be performed with wind speeds lower than $0.6 \mathrm{~m} \mathrm{~s}^{-1}$ and in the absence of a dominat wind direction. Otherwise, the resulting radial water distribution curve will not be suitable and it will provide erroneous results. Many tests in our single sprinkler experiment were not suitable mainly due to a predominance of the wind direction during the test and in some cases to an increase in wind speed during the test. In $50 \%$ of the tests the wind direction frequency was higher than $34 \%$ invalidating the results. All tests with wind speed higher than $1.5 \mathrm{~m} \mathrm{~s}^{-1}$ were also discarded in this study. Therefore only 8 out of the 26 tests carried out were suitable for the determination of the radial water distribution.

The introduction of new sprinkler with plastic nozzles in the solid set systems offers some advantages to the farmers but a detailed analysis of this type of sprinkler is needed in order to establish their reliuability. Comparison of the radial water distribution from the plastic nozzle sprinkler (RC130-BY) with the same sprinkler model but with brass nozzles (RC130L) showed in general a different shape of distribution. Only for the nozzle diameters of $4.4+2.5 \mathrm{~mm}$ at 200 and $300 \mathrm{kPa}$ operating pressure was the radial water distribution similar in both sprinklers.

The CUC of a solid set can be calculated for different wind conditions using sprinkler simulation models, but in order to have reliable results, the model should include calibration and validation of this particular material and the characterisation of the radial water distribution is required to apply the simulation model.

As previously reported in other studies for impact sprinklers, a linear relationship was found between the CUC and $U$ for our results of the experimental solid set equipped with plastic 
nozzles sprinklers $\left(\mathrm{R}_{\mathrm{adj}}^{2}=0.75\right.$; RMSE $\left.=1.9 \%\right)$. However the best suited regression equation to predict WDEL uses wind speed and the nozzle diameter as the explicative variables for the experimental solid set $\left(R^{2}\right.$ adj $\left.=0.85 ; R M S E=1.4 \%\right)$. It must be noticed that these functions are restricted to a specific sprinkler design and to a rectangular solid-set arrangement of $18 \mathrm{~m} \times 18 \mathrm{~m}$.

Comparison of the measured CUC values of the experimental solid set (Rectangular $18 \times 18 \mathrm{~m}$ ) equipped with sprinkler model RC130-BY and the experimental solid set (Triangular $18 \times 18 m$ ) with the RC130-L of Playán et al. (2006) showed that CUC values of the RC130-L sprinkler were around 5\% higher than the RC130-BY sprinkler. It may appear that the $\mathrm{RC} 130-\mathrm{L}$ sprinkler is better than the RC130-BY, however, this comparison is limited because Playán et al. (2006) evaluated the RC130-L sprinkler with only a main nozzle diameter of 4.4, pressure ranging between 328 and $350 \mathrm{kPa}$, wind speed ranging between 0.6 to $4.4 \mathrm{~m} \mathrm{~s}^{-1}$ and in a solid-set triangular configuration with $18 \times 18 \mathrm{~m}$ spacing.

Comparing the measured CUC values of the experimental solid-set equipped with RC130-BY sprinklers and the simulated values for the same solid-set with the RC130-L sprinklers under the same operational and meteorological conditions, showed relatively similar results in both sprinkler models. However, the linear regression of the CUC data was not coincident, showing a different performance of both types of sprinklers when the operation and meteorological conditions change. Under low wind conditions, the CUC of the two sprinklers was similar and high (average CUC of $89 \%$ ). However, under medium wind conditions $(1.5 \mathrm{~m}$ $\mathrm{s}^{-1} \leq \mathrm{U} \leq 4.0 \mathrm{~m} \mathrm{~s}^{-1}$ ) the CUC of the RC130-BY sprinklers was more affected (average of 78\%) than the RC130-L sprinklers (average CUC of $87 \%$ ) and in high windy conditions ( $\mathrm{U} \geq 4 \mathrm{~m} \mathrm{~s}^{-}$ $\left.{ }^{1}\right)$, the RC130-BY sprinklers had better CUC values.

The results presented show that the choice of the sprinkler model is complex because it depends on many factors, and many of these factors are out of the control of the farmer. However, the performance differences found between the sprinkler with brass or plastic 
nozzles do not justify alone the selection of a particular type of sprinkler. Other economic and technical factors should be taken into account. Empirical models such as Ador-sprinkler are extremely useful tools for decision making since they allow the simulation of the sprinkler irrigation performance under very different operational and meteorological conditions. The specific information of the sprinkler used in this study will be incorporated into the Adorsprinkler model to allow the simulation of solid-sets equipped with the RC130-BY sprinkler.

\section{ACKNOWLEDGEMENTS}

The authors sequence in this paper follows the "first-last-author-emphasis" norm. This research was funded by the MCINN of the Government of Spain through grants AGL200766716-C03-01/02, AGL2010-21681-C03-01/03; the European Commission through grant QUALIWATER (INCO-CT-2005-015031) and by the FPI-MICINN PhD grants programme. The authors would like to thank the support provided by the CITA/CSIC field staff and technicians: Miguel Izquierdo, Jesus Gaudó, Juan Manuel Acín and Ricardo Santolaria. 


\section{REFERENCES}

Anonymous. (1987). Procedure for sprinkler distribution testing for research purposes. ASAE, St. Joseph, MI, USA: 487-489.

Anonymous. (1990). Agricultural irrigation equipment. Rotating sprinklers. Part 2. Uniformity of distribution and test methods. ISO standard 7749/2. ISO. Geneva, Switzerland.

Anonymous. (1995). Agricultural irrigation equipment. Rotating sprinklers. Part 1. Design and operational requirements. ISO standard 7749/1. ISO. Geneva, Switzerland.

Bautista-Capetillo C.F., Salvador R., Burguete J., Montero J., Tarjuelo J.M., Zapata N., González J., Playán E. (2009). Comparing methodologies for the characterization of water drops emitted by an irrigation sprinkler. Transactions of the ASABE 52 (5): 1493-1504.

Carrión P., Tarjuelo J. M., Montero J. (2001). SIRIAS: a simulation model for sprinkler irrigation I. Description of model. Irrigation Science 20 (2): 73-84.

Christiansen J.E. 1942. Irrigation by sprinkling. California Ag. Expt. Sta. Bulletin 670 . University of California. Berkeley.

Dechmi F., Playán E., Cavero J., Faci J. M., Martinez-Cob A. (2003). Wind effects on solid set sprinkler irrigation depth and yield of maize (Zea mays). Irrigation Science. 22: 67-77.

Dechmi F., Playan E., Cavero J., Martinez-Cob A.,Faci J. M. (2004a). Coupled crop and solid set sprinkler simulation model. I: Model development. Journal of Irrigation and Drainage Engineering-ASCE 130 (6): 499-510.

Dechmi F., Playán E., Cavero J., Martinez-Cob A., Faci J. M. (2004b). A coupled crop and solid-set sprinkler simulation model: II. Model application. Journal of Irrigation and Drainage Engineering-ASCE 130 (6): 511-519.

Dolado J. (1999). Validez de las predicciones en la estimación de costes (Validity of predictions in the cost estimate). Universidad Del Pais Vasco, Bilbao, Spain. 
Faci J.M., Bercero A. (1991). Efecto del viento en la uniformidad y en las pérdidas por evaporación y arrastre en el riego por aspersión. Investigación Agraria. Producción y Protección Vegetales 6 (2). (In Spanish).

Faci J. M., Salvador R., Playán E., Sourell H. (2001). A comparison of fixed and rotating spray plate sprinklers. Journal of Irrigation and Drainage Engineering-ASCE 127 (4), 224233.

Keller J., Bliesner R. D. (1990). Sprinkler and trickle irrigation. Van Nostrand Reinhold, New York, NY. 652 pp.

Kincaid D.C. (1982). Sprinkler pattern radius. Transactions of the ASAE 25 (6): 1668-1672.

Kincaid D.C., Solomon K.H., Oliphant, J.C. (1996). Drop size distributions for irrigation sprinklers. Transactions of the ASAE. 39(3):839-845.

King B.A., Winward T.W., Bjorneberg D.L. (2010). Laser precipitation monitor for measurement of drop size and speed of moving spray-plate sprinklers. Applied Engineering in Agriculture 26 (2): 263-271.

Kohl R.A. (1974). Drop size distribution from medium-sized agricultural sprinklers. Transactions of the ASAE 17 (4): 690-693.

Li J.S. (1996). Sprinkler performance as function of nozzle geometrical parameters. Journal of Irrigation and Drainage Engineering-ASCE 122 (4): 244-247.

Li J.S., Kawano H. (1998). Sprinkler performance as affected by nozzle inner contraction angle. Irrigation Science 18: 63-66.

Lorenzini G., De Wrachien D. (2005). Performance assessment of sprinkler irrigation systems: A new indicator for spray evaporation losses. Irrigation and Drainage 54 (3): 295305.

Merriam J.L., Keller J. (1978). Farm irrigation system evaluation: a guide for management. Utah State University, Logan, Utah. 271 pp. 
Montero J. (1999). Análisis de la distribución de agua en sistemas de riego por aspersión estacionario. Desarrollo del modelo de simulación de riego por aspersión (SIRIAS). Doctoral thesis, Universidad de Castilla La Mancha, Albacete, Spain.

Playán E., Salvador R., Faci J. M., Zapata N., Martínez-Cob A., Sanchez I. (2005). Day and night wind drift and evaporation losses in sprinkler solid-sets and moving laterals. Agricultural Water Management 76(3): 139-159.

Playán E., Zapata N., Faci J. M., Tolosa D., Lacueva J. L., Pelegrin J., Salvador R., Sánchez I., Lafita A. (2006). Assessing sprinkler irrigation uniformity using a ballistic simulation model. Agricultural Water Management 84 (1-2): 89-100.

Playán E., Zapata N., Burguete J., Salvador R., Serreta A. (2010). Application of a topographic 3D scanner to irrigation research. Irrigation science 28 (3): 245-256.

Sánchez I., Zapata N., Faci J. M. (2010a). Combined effect of technical, meteorological and agronomical factors on solid-set sprinkler irrigation: I. Irrigation performance and soil water recharge in alfalfa and maize. Agricultural Water Management 97 (10): 1571-1581.

Sánchez I., Zapata N., Faci J. M. (2010b). Combined effect of technical, meteorological and agronomical factors on solid-set sprinkler irrigation: II. Modifications of the wind velocity and of the water interception plane by the crop canopy. Agricultural Water Management 97(10): 1591-1601.

Sánchez I., Faci J. M., Zapata N. (2011). The effects of pressure, nozzle diameter and meteorological conditions on the performance of agricultural impact sprinklers. Agricultural Water Management 102(1): 13-24.

Seginer I., Nir D., von Bernuth R.D. (1991a). Simulation of wind-distorted sprinkler patterns. Journal of Irrigation and Drainage Engineering-ASCE. 117:285-305.

Seginer I., Kantz D., Nir D. (1991b). The Distortion by Wind of the Distribution Patterns of Single Sprinklers. Agricultural Water Management 19(4): 341-359. 
Stambouli T., Martínez-Cob A., Faci J. M., Howell T., Zapata N. (2012). Sprinkler evaporation losses in alfalfa during solid-set sprinkler irrigation in semiarid areas. Irrigation Science. DOI 10.1007/s00271-012-0389-2

Tarjuelo J.M. 1995. El riego por aspersión y su tecnología. Mundiprensa, Madrid, Spain.

Tarjuelo J.M., Montero J., Valiente M., Honrubia F.T., Ortiz J. (1999a). Irrigation uniformity with medium size sprinklers part I: Characterization of water distribution in no-wind conditions. Transactions of the ASAE 42 (3): 665-676.

Tarjuelo J.M., Montero J., Carrión P.A., Honrubia F. T., Calvo A. (1999b). Irrigation uniformity with medium size sprinklers part II: Influence of wind and other factors on water distribution. Transactions of the ASAE 42 (3): 677-690.

Tarjuelo J.M., Montero J., Honrubia F. T., Ortiz J. J., Ortega J.F. (1999c). Analysis of uniformity of sprinkler irrigation in a semi-arid area. Agricultural Water Management (40): 315-331.

Tarjuelo J.M, Ortega J.F, Montero J., De Juan J.A. (2000). Modelling evaporation and drift losses in irrigation with medium size impact sprinklers under semi-arid conditions. Agricultural Water Management, 43 (3) 263-284.

Yazar A. (1984). Evaporation and drift losses from sprinkler irrigation systems under various operating conditions. Agricultural Water Management 8: 439-449.

Yu G.J., Gao Z.Y., Huang J.S. (2009). Experimental research on sprinkler irrigation evaporation and drift losses in arid sandstorm regions. International Symposium of HAI Basin Integrated Water and Environment Management, 2008. Beijing, China. River basin research and planning approach: 450-456. Published in 2009 by Orient Acad Forum, Marrickville (Australia).

Wilcox B.P., Rawls W.J., Brakensiek D.L., Wight J.R. (1990). Predicting runoff from rangeland catchments: A comparison of two models. Water Resources Research 26(10):2401-2410. 
Willmott C.J. (1981). On the validation of models. Phys. Geog. 2:184-194

Zapata N., Playán E., Martínez-Cob, A., Sánchez I., Faci J. M., Lecina, S. (2007). From onfarm solid-set sprinkler irrigation design to collective irrigation network design in windy areas. Agricultural Water Management 87 (2): 187-199. 


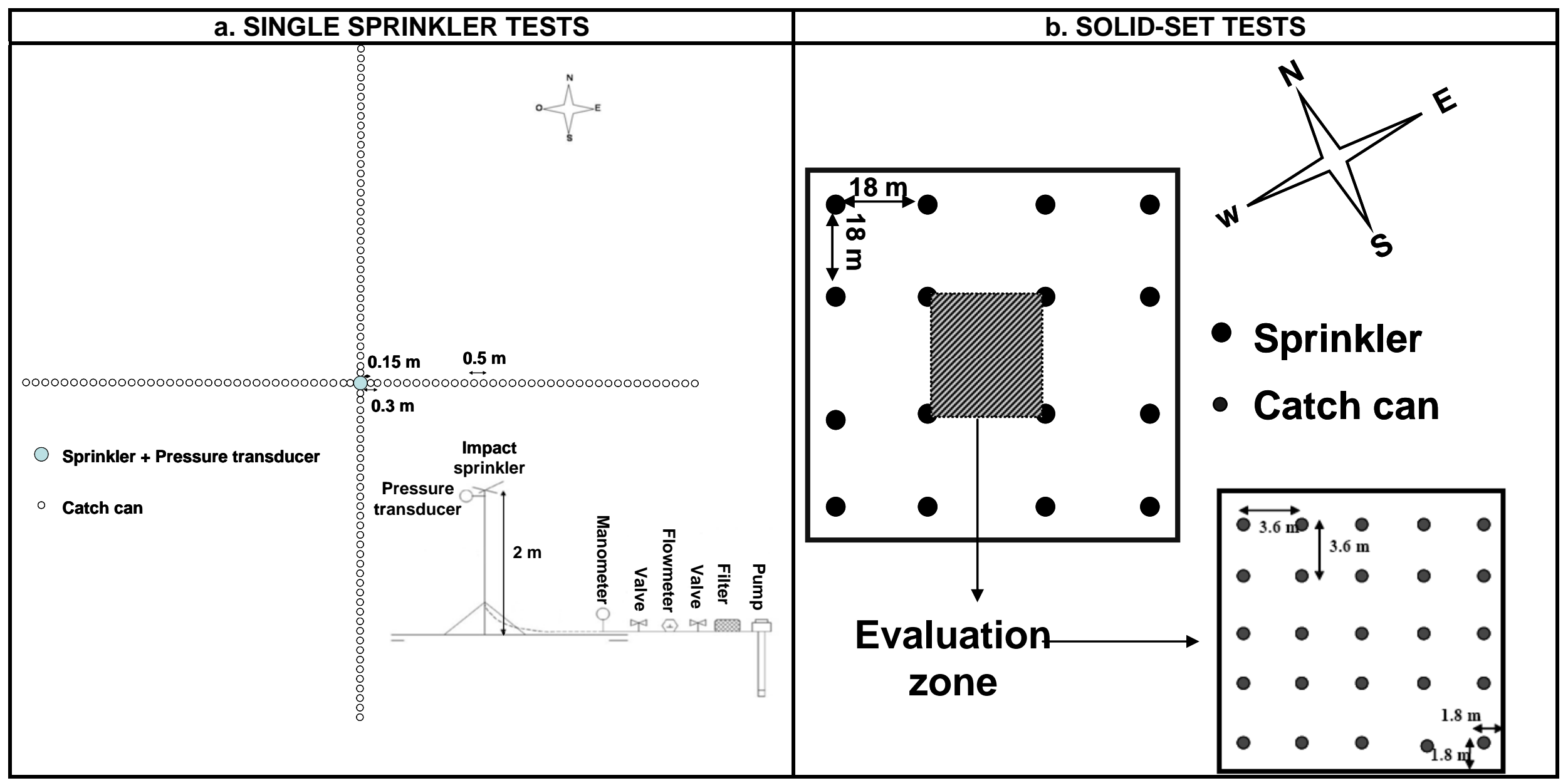

Fig. 1. a. On-farm arrangement of the pluviometers and facilities for the isolated sprinkler experiment to determine the radial curves for the RC130-BY sprinkler. b. Arrangement of the experimental solid-set and network of pluviometers in the central sprinkler spacing of the experimental solid-set. 


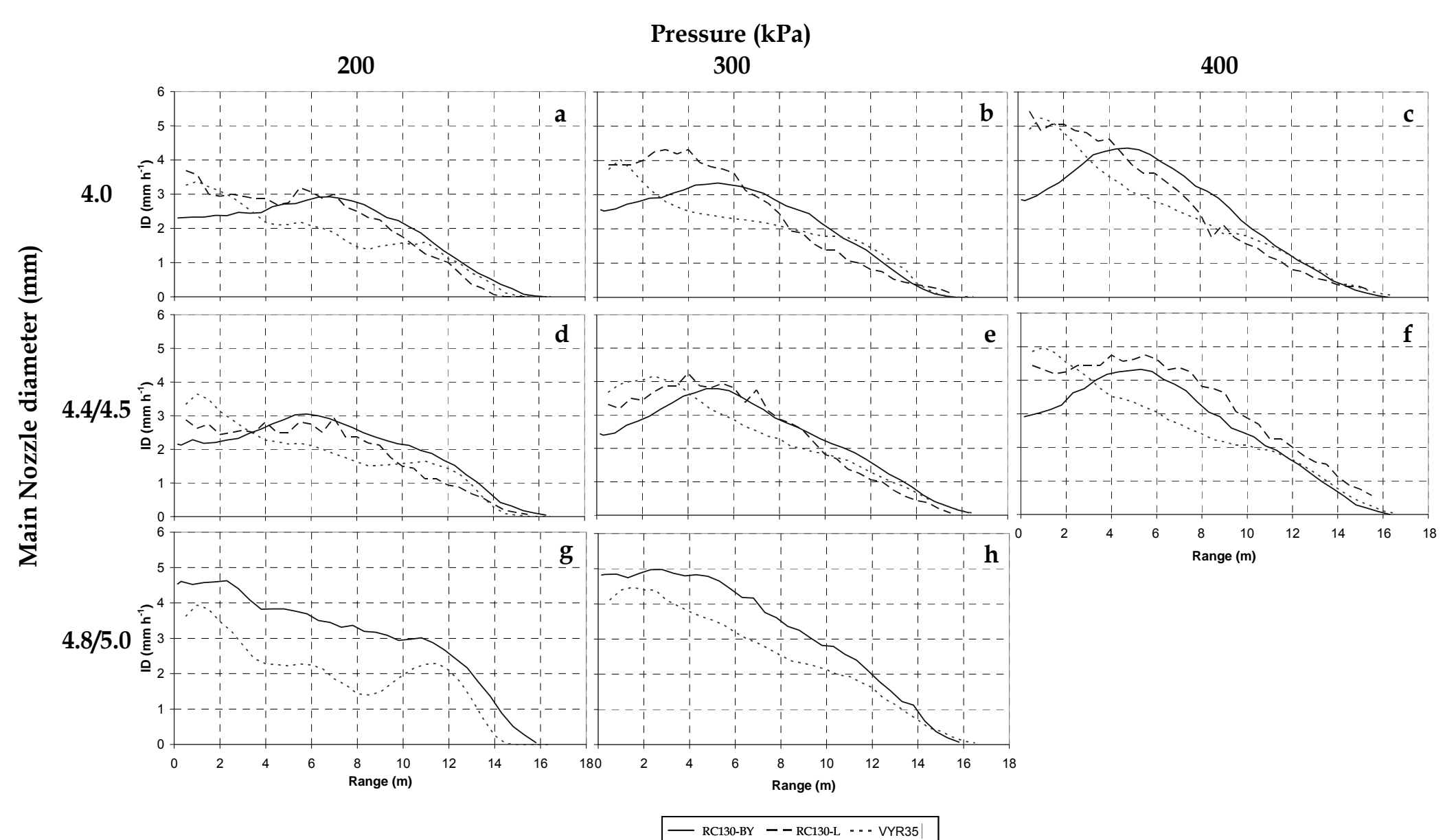

Fig. 2. Average irrigation depth (ID, $\mathrm{mm} \mathrm{h}^{-1}$ ) collected along the wetted radius of the sprinkler (Rad) for the RC130-BY sprinkler with three main nozzle diameters $(4,4.5$ and $5 \mathrm{~mm}$ ) and three operating pressures. Radial curves of sprinklers RC130-L and VYR-35 are included for comparison purposes. Main nozzle diameters of RC130-L were 4 and $4.4 \mathrm{~mm}$. Main nozzle diameters of VYR35 were 4, 4.4 and $4.8 \mathrm{~mm}$. In all cases an auxiliary nozzle was used (2.5 mm diameter in the RC130-BY and $2.4 \mathrm{~mm}$ diameter in the RC130-L and VYR35). 


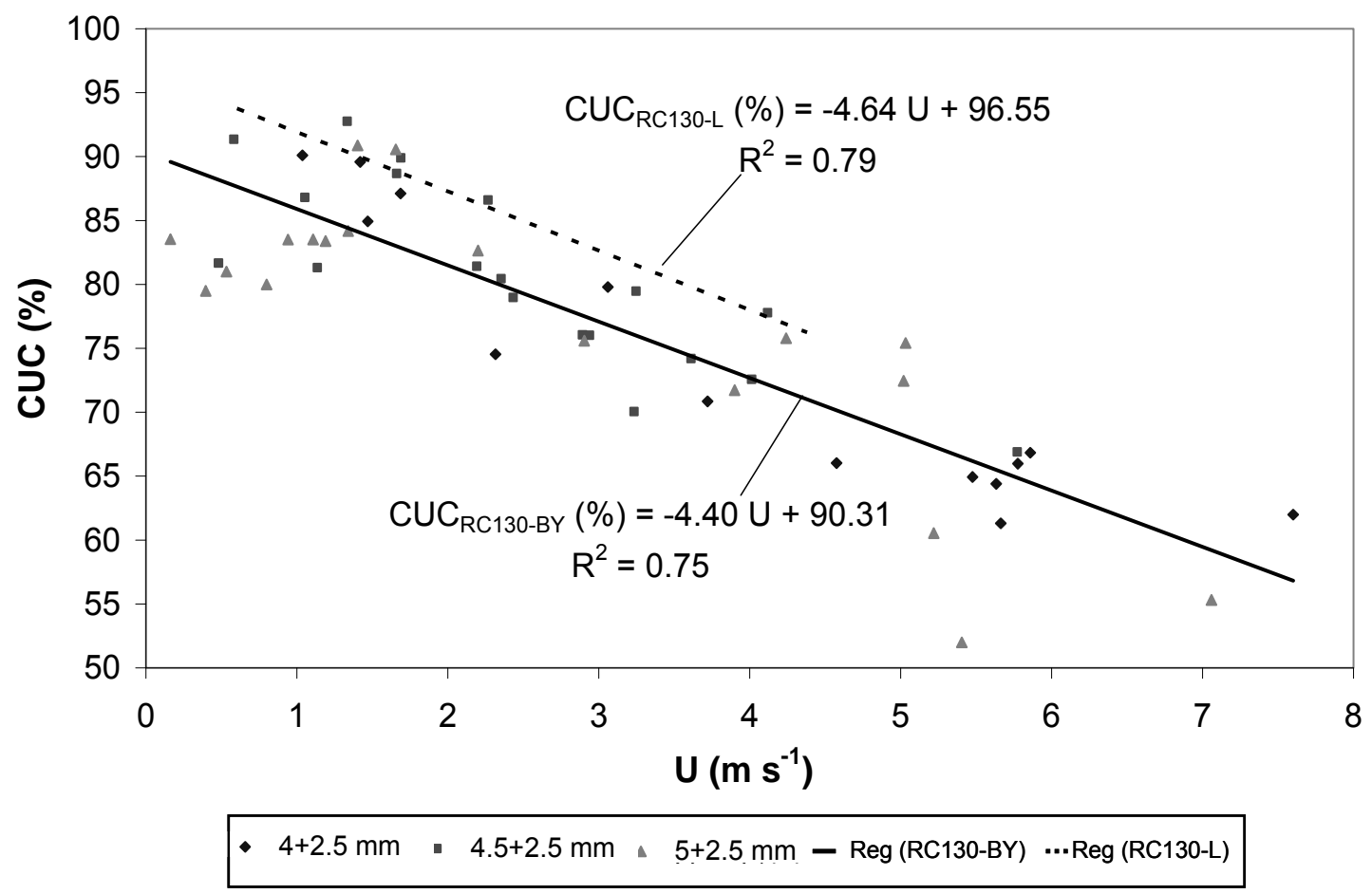

Fig. 3. Relationship between the Christiansen uniformity coefficient (CUC) and wind speed (U) for the RC130-BY sprinkler in a solid-set with a rectangular spacing of $18 \mathrm{~m}$ by $18 \mathrm{~m}$ $(R 18 \times 18)$. Individual points correspond to the evaluations with different nozzle diameter $D$ $(4+2.5,4.5+2.5$ and $5+2.5 \mathrm{~mm})$. Black line represents the linear regression of all experimental points. Dashed line represents the linear regression found by Playán et al. (2006) for a solid set with RC130-L sprinklers with nozzle diameters $4.4+2.4 \mathrm{~mm}$, operating pressure ranging between 335 and $360 \mathrm{kPa}$ at a triangular $18 \mathrm{~m}$ by $18 \mathrm{~m}$ spacing. Linear regression equations are presented in the figure. 


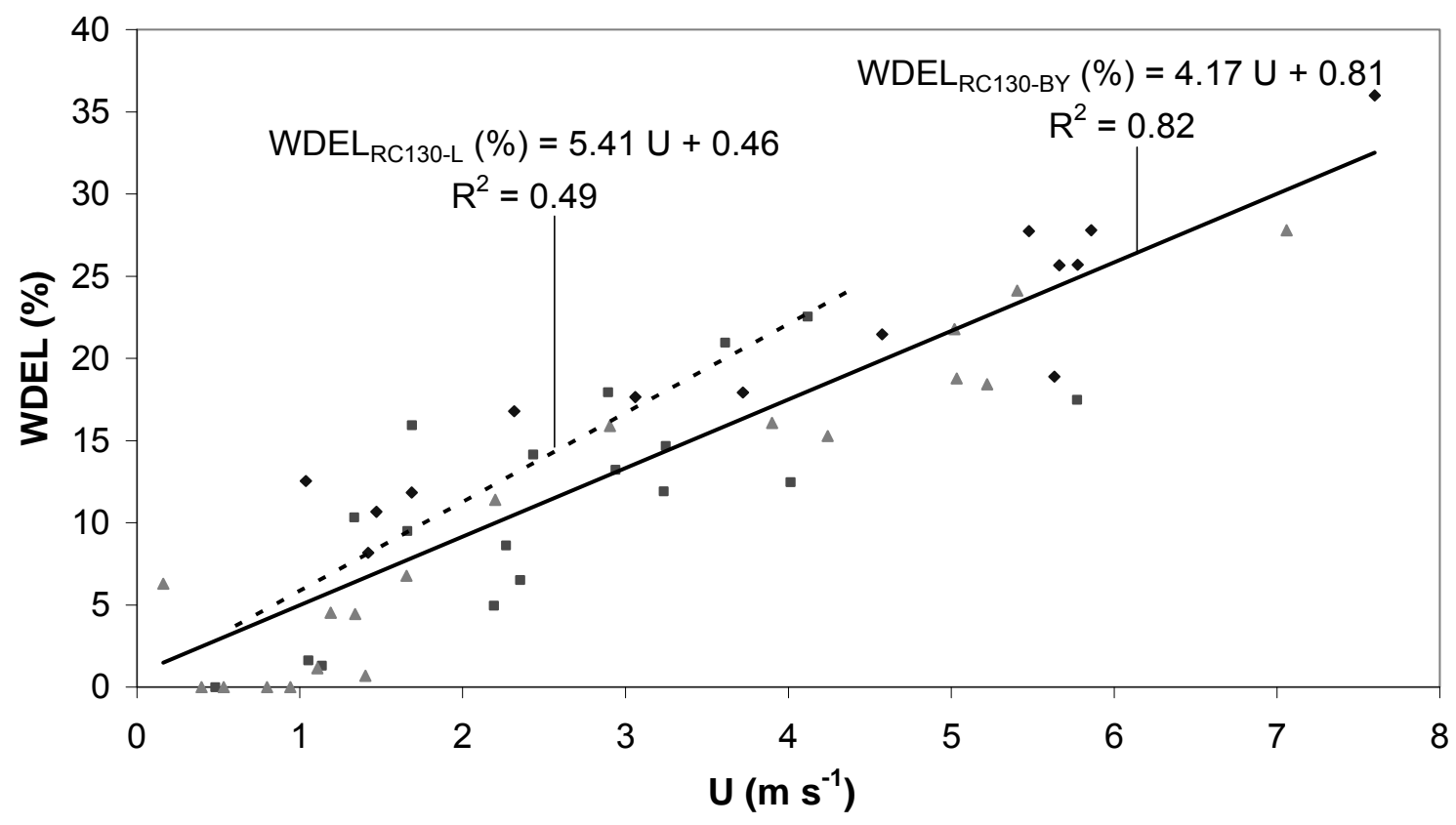

- $4+2.5 \mathrm{~mm}$ - $4.5+2.5 \mathrm{~mm} \triangle 5+2.5 \mathrm{~mm}-\operatorname{Reg}(\mathrm{RC} 130-\mathrm{BY}) \quad \cdots \operatorname{Reg}(\mathrm{RC} 130-\mathrm{L})$

Fig. 4. Relationship between wind drift and evaporation losses (WDEL) and wind speed (U) for the RC130-BY sprinkler arranged in a solid-set at a rectangular spacing of $18 \mathrm{~m}$ by $18 \mathrm{~m}$ $(R 18 \times 18)$. Individual points correspond to the evaluations with different nozzle diameter $D$ $(4+2.5,4.5+2.5$ and $5+2.5 \mathrm{~mm})$. Black line represents the linear regression of all experimental points. Dashed line represents the linear regression found by Playán et al. (2006) for a solid set with RC130-L sprinklers with nozzle diameters $4.4+2.4 \mathrm{~mm}$, operating pressure ranging between 335 and $360 \mathrm{kPa}$ at a triangular $18 \mathrm{~m}$ by $18 \mathrm{~m}$ (T18x18) spacing. Linear regression equations are presented in the figure. 


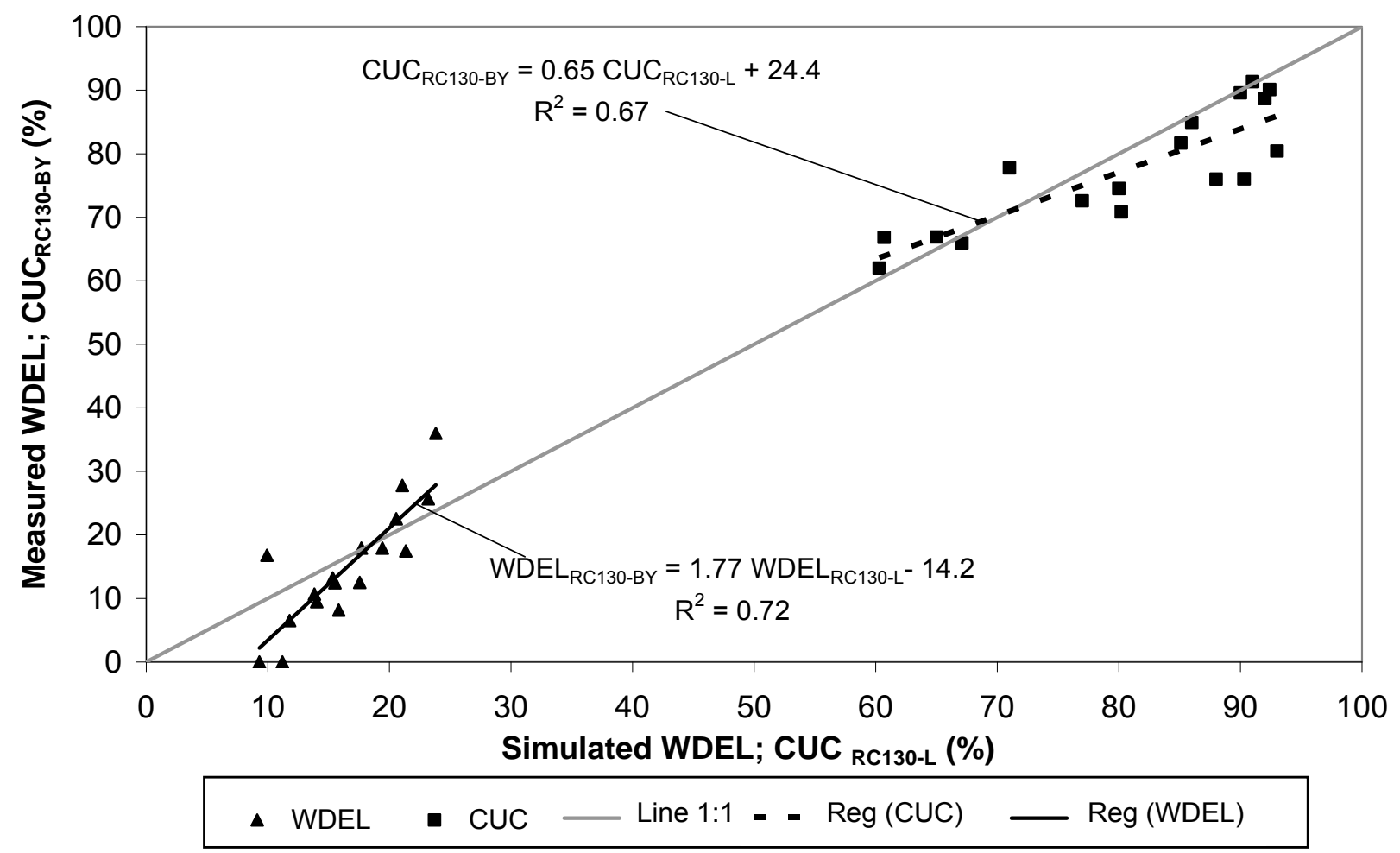

Fig. 5. Linear regressions of measured wind drift and evaporation losses (WDEL) and Christiansen uniformity coefficient (CUC) in the experimental solid-set evaluations with the RC130-BY sprinkler compared with the corresponding values of simulated WDEL and CUC with the Ador sprinkler model (Playán et al., 2006) for the same solid set arrangement and operation conditions with the RC130-L sprinkler. Grey line represents the 1:1 line. Regression equations are presented in the figure. 


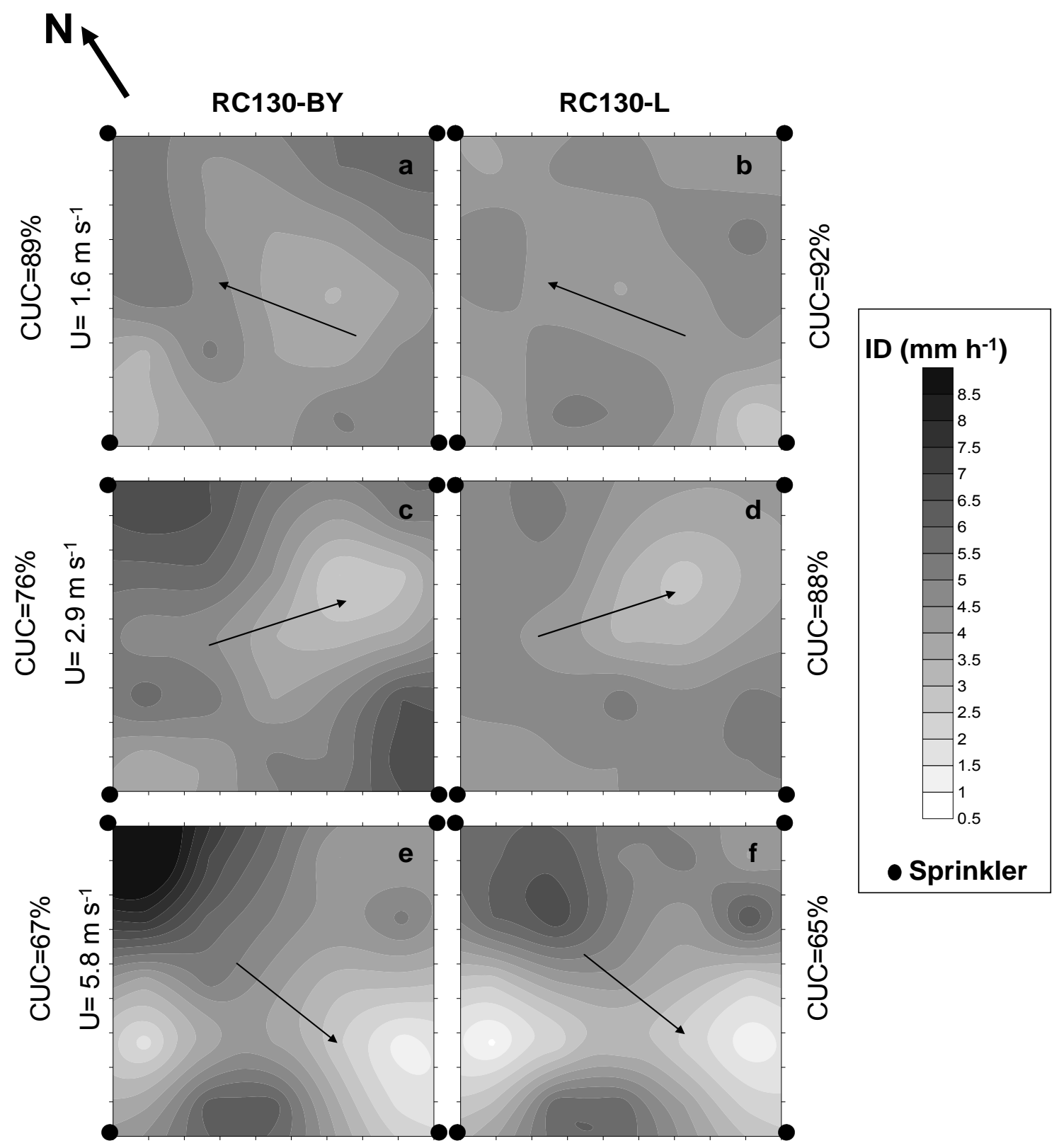

Fig. 6. Contour maps of the water distribution pattern (ID, $\mathrm{mm} \mathrm{h}^{-1}$ ) for the experimental solidset with the evaluated RC130-BY sprinkler and simulated for the RC130-L sprinkler with nozzle diameters of 4.5 and $2.5 \mathrm{~mm}$ at a working pressure of $300 \mathrm{kPa}$ with three values of wind speed $(\mathrm{U})$. Figures on the left column corresponds to the RC130-BY sprinkler and on the right corresponds to the RC130-L. Arrows indicate the prevailing wind direction during each event. Wind speed (U) and Christiansen uniformity coefficient (CUC) are indicated in the figures. 
Table 1. Operational and meteorological conditions for the 26 single sprinkler tests performed with the RC130-BY sprinkler: diameter of the main and auxiliary nozzles $(D+d$, $\mathrm{mm})$, operating pressure $(\mathrm{p}, \mathrm{kPa})$, irrigation time $(\mathrm{IT}, \mathrm{h})$, sprinkler discharge $\left(\mathrm{Q}, \mathrm{L} \mathrm{h} \mathrm{h}^{-1}\right)$, average air temperature $\left(T,{ }^{\circ} \mathrm{C}\right)$, average air relative humidity $(\mathrm{RH}, \%)$, average standard deviation of the irrigation depth between the four radii (SD ID, $\mathrm{mm} \mathrm{h}^{-1}$ ), average wind speed $\left(\mathrm{U}, \mathrm{m} \mathrm{s}^{-1}\right)$, average wind direction (WD) and dominant wind direction frequency ( $\left.\mathrm{Fr}, \%\right)$.

\begin{tabular}{|c|c|c|c|c|c|c|c|c|c|}
\hline \multirow{2}{*}{$\begin{array}{c}\mathrm{D}+\mathrm{d} \\
(\mathrm{mm})\end{array}$} & \multirow{2}{*}{$\begin{array}{c}P \\
(k P a)\end{array}$} & \multirow{2}{*}{$\begin{array}{l}\text { IT } \\
\text { (h) }\end{array}$} & \multirow{2}{*}{$\begin{array}{c}Q \\
\left(L h^{-1}\right)\end{array}$} & \multirow{2}{*}{$\begin{array}{c}\mathrm{T} \\
\left({ }^{\circ} \mathrm{C}\right)\end{array}$} & \multirow{2}{*}{$\begin{array}{l}\text { HR } \\
\text { (\%) }\end{array}$} & \multirow{2}{*}{$\begin{array}{c}\text { SD ID } \\
\left(\mathrm{mm} \mathrm{h}^{-1}\right)\end{array}$} & \multicolumn{3}{|c|}{ WIND } \\
\hline & & & & & & & $\underset{\left(\mathrm{m} \mathrm{s}^{-1}\right)}{\mathrm{U}}$ & WD & $\begin{array}{l}\text { Fr. } \\
\text { (\%) }\end{array}$ \\
\hline \multirow{12}{*}{$\begin{array}{l}\stackrel{0}{N} \\
\stackrel{+}{+}\end{array}$} & 200 & 2.0 & 1138 & 7.2 & 90 & 0.40 & 1.1 & NW & 50 \\
\hline & 194 & 2.0 & 1140 & 17.7 & 47 & 0.21 & 0.7 & ENE & 50 \\
\hline & 196 & 3.5 & 1140 & 27.2 & 46 & 0.11 & 1.0 & SE & 14 \\
\hline & 277 & 2.0 & 1377 & 21.7 & 44 & 0.10 & 0.7 & SW & 75 \\
\hline & 285 & 2.0 & 1400 & 9.2 & 71 & 0.18 & 0.8 & $\mathrm{~S}$ & 25 \\
\hline & 271 & 1.9 & 1346 & 28.5 & 45 & 0.18 & 0.8 & $\mathrm{ENE} / \mathrm{NE}^{+}$ & 34 \\
\hline & 386 & 2.0 & 1567 & 9.2 & 64 & 0.39 & 1.1 & $\mathrm{~N}$ & 25 \\
\hline & 386 & 2.0 & 1570 & 12 & 63 & 0.56 & 0.3 & $\mathrm{SW} \mathrm{SSW}{ }^{+}$ & 80 \\
\hline & 388 & 2.0 & 1580 & 14 & 67 & 0.36 & 0.6 & SSE & 75 \\
\hline & 390 & 2.0 & 1593 & 14.6 & 53 & 0.80 & 1.2 & $S$ & 33 \\
\hline & 360 & 3.0 & 1544 & 22.4 & 47 & 0.48 & 1.2 & $\mathrm{SW} \mathrm{SSW}^{+}$ & 50 \\
\hline & 400 & 2.0 & 1678 & 24.3 & 48 & 0.16 & 0.9 & NW & 22 \\
\hline \multirow{11}{*}{ 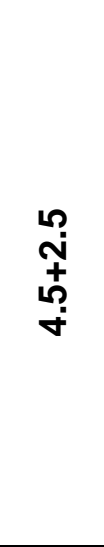 } & 173 & 1.9 & 1312 & 13.5 & 52 & 0.29 & 0.8 & WNW & 75 \\
\hline & 175 & 2.0 & 1298 & 6.7 & 89 & 0.13 & 0.3 & SE & 50 \\
\hline & 188 & 2.0 & 1411 & 24.3 & 45 & 0.24 & 0.6 & $\mathrm{~N}$ & 20 \\
\hline & 183 & 2.1 & 1390 & 26.8 & 52 & 0.29 & 1.0 & W & 19 \\
\hline & 198 & 1.9 & 1448 & 19.3 & 48 & 0.14 & 0.9 & NNE & 29 \\
\hline & 290 & 2.0 & 1598 & 10.2 & 80 & 0.33 & 0.3 & WNW & 75 \\
\hline & 293 & 2.0 & 1595 & 5.9 & 78 & 0.28 & 0.4 & $\mathrm{~N}$ & 75 \\
\hline & 290 & 2.0 & 1677 & 27.4 & 48 & 0.13 & 0.8 & $\mathrm{NE} \mathrm{NNE}^{+}$ & 24 \\
\hline & 369 & 2.0 & 1847 & 6.5 & 74 & 0.41 & 0.9 & NO & 25 \\
\hline & 370 & 2.0 & 1850 & 14.1 & 51 & 0.16 & 0.6 & SE & 25 \\
\hline & 372 & 2.1 & 1924 & 23.3 & 53 & 0.47 & 1.3 & $\mathrm{NW} \mathrm{WNW}^{+}$ & 60 \\
\hline \multirow{3}{*}{\begin{tabular}{l} 
ñ \\
\multirow{1}{+}{} \\
م⿱
\end{tabular}} & 214 & 2.0 & 1930 & 4.2 & 100 & 0.19 & 0.6 & NW & 33 \\
\hline & 292 & 2.1 & 2064 & 7.1 & 99 & 0.17 & 1.0 & SSO & 33 \\
\hline & 385 & 2.1 & 2372 & 11.3 & 75 & 0.30 & 1.5 & $\mathrm{~N}$ & 77 \\
\hline
\end{tabular}

The bold numbers corresponds to tests considered suitable for the characterisation of the Rad and used in this paper

+ Two wind directions were dominant 
Table 2. Summary of the 50 tests performed in the solid-set tests equipped with the RC130BY sprinkler arranged in a rectangular solid-set at $18 \mathrm{~m}$ by $18 \mathrm{~m}(\mathrm{R} 18 \times 18)$. Experiments were grouped according to nozzle diameters $(D+d, m m)$ and operation pressure range (around 200, 300 and $400 \mathrm{kPa}$ ). For each group the number of tests and the maximum and minimum values of operation pressure $(\mathrm{p}, \mathrm{kPa})$, irrigation time (IT, h), the Christiansen uniformity coefficient (CUC, \%), wind drift and evaporation losses (WDEL, \%), wind speed $(\mathrm{U}, \%)$, air temperature $\left(\mathrm{T},{ }^{\circ} \mathrm{C}\right)$ and relative humidity $(\mathrm{RH}, \%)$ of the air are presented.

\begin{tabular}{|c|c|c|c|c|c|c|c|c|c|c|c|c|c|}
\hline \multirow{2}{*}{$\begin{array}{l}D+d \\
(\mathrm{~mm})\end{array}$} & \multirow{2}{*}{$\begin{array}{l}\text { Number } \\
\text { of tests }\end{array}$} & $\begin{array}{c}\mathbf{p} \\
(k P a)\end{array}$ & \multicolumn{2}{|c|}{$\begin{array}{l}\text { IT } \\
(h)\end{array}$} & \multicolumn{2}{|c|}{$\begin{array}{l}\text { CUC } \\
(\%)\end{array}$} & \multicolumn{2}{|c|}{$\begin{array}{c}\text { WDEL } \\
(\%)\end{array}$} & \multicolumn{2}{|c|}{$\underset{\left(m s^{-1}\right)}{\mathbf{U}}$} & $\begin{array}{c}\mathrm{T} \\
\left({ }^{\circ} \mathrm{C}\right)\end{array}$ & \multicolumn{2}{|c|}{$\begin{array}{l}\text { HR } \\
(\%)\end{array}$} \\
\hline & & Max Min & Max & Min & Max & Min & Max & Min & Max & Min Max & Min & Max & Min \\
\hline \multirow{3}{*}{$\begin{array}{l}\stackrel{0}{N} \\
\stackrel{+}{+}\end{array}$} & 5 & 208190 & 2.06 & 2.0 & 85 & 65 & 27.8 & 10.7 & 5.86 & 1.4724 .9 & 21.3 & 57 & 44 \\
\hline & 5 & 328305 & 2.65 & 2.0 & 90 & 61 & 25.7 & 8.2 & 5.78 & 1.4226 .5 & 7.8 & 80 & 42 \\
\hline & 4 & 379366 & 2.34 & 2.0 & 91 & 66 & 36.0 & 10.1 & 7.60 & 1.0430 .1 & 21.0 & 6 & 37 \\
\hline \multirow{3}{*}{\begin{tabular}{l}
$\stackrel{0}{\pi}$ \\
\multirow{+}{*}{} \\
L̊ \\
$\dot{+}$
\end{tabular}} & 6 & 206188 & 2.07 & 1.6 & 82 & 70 & 21.0 & 0.0 & 4.01 & 0.4830 .0 & 18.8 & 66 & 41 \\
\hline & 7 & 344285 & 2.75 & 1.8 & 93 & 51 & 15.0 & 2.0 & 5.77 & 1.0526 .0 & 21.0 & 60 & 50 \\
\hline & 4 & 392365 & 3.27 & 1.6 & 91 & 79 & 22.6 & 0.0 & 4.12 & 0.5829 .0 & 24.5 & 72 & 43 \\
\hline \multirow{3}{*}{$\begin{array}{l}\text { N } \\
\text { N } \\
\text { ț }\end{array}$} & 8 & 222191 & 2.57 & 1.9 & 84 & 72 & 21.8 & 0.0 & 5.02 & 0.1626 .0 & 9.0 & 75 & 45 \\
\hline & 5 & 326291 & 3.01 & 2.1 & 91 & 75 & 19.0 & 0.7 & 5.03 & 1.4026 .3 & 12.0 & 74 & 43 \\
\hline & 6 & 367363 & 2.61 & 2.0 & 79 & 66 & 27.8 & 0.0 & 7.06 & 0.4024 .4 & 11.4 & 69 & 39 \\
\hline
\end{tabular}


Table 3. Comparison of measured irrigation performance parameters (depth applied, ID, uniformity coefficient of Christiansen, CUC, and wind drift and evaporation losses, WDEL) in the solid-set (R18x18) equipped with the RC130-BY sprinkler and the simulated values of CUC and WDEL for the same solid set arrangement (R18x18) with the RC130-L sprinkler under the same experimental values of irrigation time (IT), working pressure $(p)$, wind speed $(U)$ and direction $(\mathrm{WD})$, air temperature $(T)$ and relative humidity $(H R)$.

\begin{tabular}{|c|c|c|c|c|c|c|c|c|c|c|c|c|}
\hline \multirow[b]{2}{*}{$\begin{array}{c}\mathbf{D}+\mathbf{d} \\
(\mathrm{mm})\end{array}$} & \multirow[b]{2}{*}{$\begin{array}{l}\text { IT } \\
(h)\end{array}$} & \multirow[b]{2}{*}{$\begin{array}{c}\mathbf{p} \\
(k P a)\end{array}$} & \multirow[b]{2}{*}{$\underset{\left(m s^{-1}\right)}{\mathbf{U}}$} & \multirow[b]{2}{*}{ WD* } & \multirow[b]{2}{*}{$\begin{array}{c}\mathbf{T} \\
\left({ }^{\circ} \mathrm{C}\right)\end{array}$} & \multirow[b]{2}{*}{$\begin{array}{l}\text { HR } \\
(\%)\end{array}$} & \multicolumn{3}{|c|}{ Measured RC130-BY } & \multicolumn{3}{|c|}{ Simulated RC130-L } \\
\hline & & & & & & & $\begin{array}{c}\text { ID } \\
(\mathrm{mm})\end{array}$ & $\begin{array}{c}\text { WDEL } \\
(\%)\end{array}$ & $\begin{array}{c}\text { CUC } \\
(\%)\end{array}$ & $\begin{array}{c}\text { ID } \\
(\mathrm{mm})\end{array}$ & $\begin{array}{l}\text { WDE } \\
\text { L (\%) }\end{array}$ & $\begin{array}{c}\text { CUC } \\
(\%)\end{array}$ \\
\hline \multirow{8}{*}{$\begin{array}{l}\stackrel{1}{N} \\
\underset{+}{+}\end{array}$} & 2.07 & 190 & 3.72 & NW & 21.3 & 54 & 7.59 & 17.9 & 71 & 7.70 & 17.7 & 80 \\
\hline & 2.13 & 202 & 1.47 & $E$ & 21.8 & 57 & 8.06 & 10.7 & 85 & 8.00 & 13.8 & 86 \\
\hline & 1.99 & 202 & 5.86 & NW & 23.3 & 52 & 7.54 & 27.8 & 67 & 7.40 & 21.1 & 61 \\
\hline & 1.99 & 305 & 5.78 & NW & 26.5 & 42 & 9.25 & 25.7 & 66 & 9.10 & 23.2 & 67 \\
\hline & 1.97 & 310 & 1.42 & $E$ & 25.5 & 47.5 & 9.24 & 8.2 & 90 & 9.00 & 15.8 & 90 \\
\hline & 2.65 & 316 & 2.32 & W & 7.8 & 81 & 12.55 & 16.8 & 75 & 12.10 & 9.9 & 80 \\
\hline & 1.98 & 367 & 1.04 & SW & 30.9 & 37 & 10.13 & 12.5 & 90 & 10.10 & 17.6 & 92 \\
\hline & 2.27 & 379 & 7.60 & NW & 18.5 & 51 & 11.75 & 36.0 & 62 & 11.60 & 23.8 & 60 \\
\hline \multirow{9}{*}{ 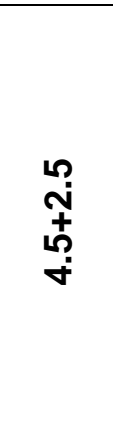 } & 1.58 & 188 & 4.01 & NNW & 18.8 & 66 & 6.89 & 12.5 & 73 & 6.80 & 15.5 & 87 \\
\hline & 1.75 & 194 & 0.48 & $\mathrm{NE}$ & 21.7 & 63 & 7.74 & 0.0 & 82 & 7.60 & 11.2 & 85 \\
\hline & 2.07 & 205 & 2.89 & WSW & 29.9 & 41 & 9.39 & 17.9 & 76 & 8.90 & 19.4 & 90 \\
\hline & 2.75 & 292 & 1.66 & SSE & 24.8 & 58 & 14.90 & 9.5 & 89 & 14.50 & 14.0 & 92 \\
\hline & 2.01 & 302 & 5.77 & NW & 21.1 & 50 & 11.06 & 17.5 & 67 & 10.60 & 21.4 & 65 \\
\hline & 2.42 & 305 & 2.94 & WSW & 24.9 & 60 & 13.39 & 13.2 & 76 & 12.80 & 15.3 & 88 \\
\hline & 3.27 & 365 & 4.12 & NW & 28.9 & 43 & 19.79 & 22.5 & 78 & 19.30 & 20.6 & 71 \\
\hline & 1.58 & 385 & 0.58 & NW & 22.3 & 72 & 9.86 & 0.0 & 91 & 9.60 & 9.3 & 91 \\
\hline & 2.42 & 392 & 2.35 & $S$ & 24.5 & 72 & 15.17 & 6.5 & 80 & 14.80 & 11.8 & 93 \\
\hline
\end{tabular}

* Prevailing wind direction 